\title{
Virtual Prototype Design of Double Disc Mower Drive Bracket Based on ANSYS Workbench
}

\author{
Ning Zhang ${ }^{1}$, Manquan Zhao ${ }^{1}$, Yanhua $\mathrm{Shi}^{2}$, and Yueqin $\mathrm{Liu}^{3}$ \\ ${ }^{1}$ Mechanical and Electrical Engineering College of Inner Mongolia Agricultural University, \\ Hohhot, 010018, China \\ \{lyuzhangning, nmgzmq\} @163.com \\ ${ }^{2}$ College of Mechanical and Electrical Engineering of Wuhan Polytechnic University, \\ Wuhan, 430023, China \\ shiyanhua122@163.com \\ ${ }^{3}$ Mechanical and Electrical Engineering of Inner Mongolia Technical \\ College of Mechanics and Electrics, Hohhot, 010070, China \\ 853945990 @qq. com
}

\begin{abstract}
During the double disc mower structural design process, static analysis is an extremely important field, not only decide to what the structure size is, but also for the subsequent fatigue analysis, providing the basis for the overall stability analysis. Now the traditional domestic design mainly based on the empirical design, which is resulted in Performance indicators lag behind of the mower, focusing on the performance of vibration is too large and the structure is irrational. Therefore, optimizing the structure of the mower to improve the vibration situation has important significance. Using SolidWorks software to build the three-dimensional solid model of the first mower driveline, and then import the model into ANSYS Workbench to establish the finite element analysis model, through the finite element and modal analysis of the results obtained the stress and strain distribution of the natural frequencies and mode shapes characteristic, providing an important basis for further design optimization of mower structure.
\end{abstract}

Keywords: Double disc mower, Virtual Prototyping, Optimization design, Finite element analysis, ANSYS workbench.

\section{Introduction}

For a long time, due to the complexity of agricultural machinery work objects, there is a big difficulty during the process of the agricultural machinery design development, some theoretical analysis are complex, in addition, computation is intensive[1-3]. Traditional agricultural machinery product development process usually go through the prototype design, test, field test, improve the design, retrial and other steps, during the design development process, there are some fatal flaws, namely the high cost, long cycle, poorly designed, low precision relatively complex institutional analysis and synthesis problems, many mechanism parameters are depended on the designers' experience, which is seriously hampered the improvement of the products quality. 
During the modern machine design, optimal design of the mechanical structure is an indispensable part, it has a significant effect on the performance of the whole mechanical structure [4]. Traditional optimization design method is cumbersome and solving complex, accuracy is also difficult to meet the requirements. With the rapid development of the computer technology, a variety of simulation software capabilities matured and improved, and then the process of structural optimization is feasible, analysis results is visualized, to infuse a new strength into the mechanical optimizing design of the structural design. Using ANSYS workbench ANSYS Workbench to establish the finite element analysis model, which is an inevitable trend for the future of mechanical design optimization design to improve the structural optimization of efficiency and accuracy and shorten the production development cycles.

\section{Overall Program to Determine}

9YG-130 front mounted dual disc mower, is mainly used in cutting and laying grass strip operation, the machine design is reasonable, easy to operate, reliable, and stable performance et al, which is an ideal promotion models for farmers to use.

9YG-130 dual disc mower is connected by tractor yoke1, the first stage drive system 2, transmission and manual clutch 3, mower frame 4, the cutting member 5 , four-bar linkage 6, the lift cylinder 7 and the other components, as is shown in Fig.1.

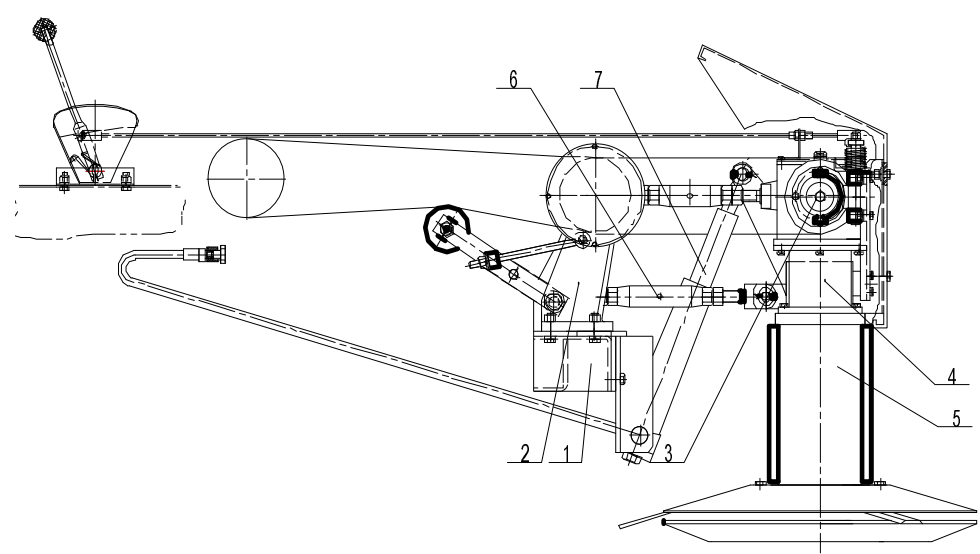

1. Tractor yoke 2.The first stage drive system 3. Transmission and manual clutch 4. Mower frame 5. The cutting member 6. Four bar linkage 7. Lift cylinder

Fig. 1. 9YG-130 model double disc mower

\subsection{Create the Double Disc Mower Three-dimensional Model}

Founding accurate, and reliable compute model is one of the important steps for dual disc mower finite element analysis to apply the finite element method [5]. Because the modeling capabilities of three-dimensional ANSYS Workbench is weaken, Using 
SolidWorks software to build the first stage drive system 3D solid model. To facilitate the analysis, under the premise of the results without prejudice aim at for the model simplify moderately. SolidWorks is applied more widely and used as a feature-based parametric 3D solid design software. Solid designers by stretching, rotating, shelling, wall thinning, arraying and punching achieve product dimensions and structural design. As is shown in Fig.2.

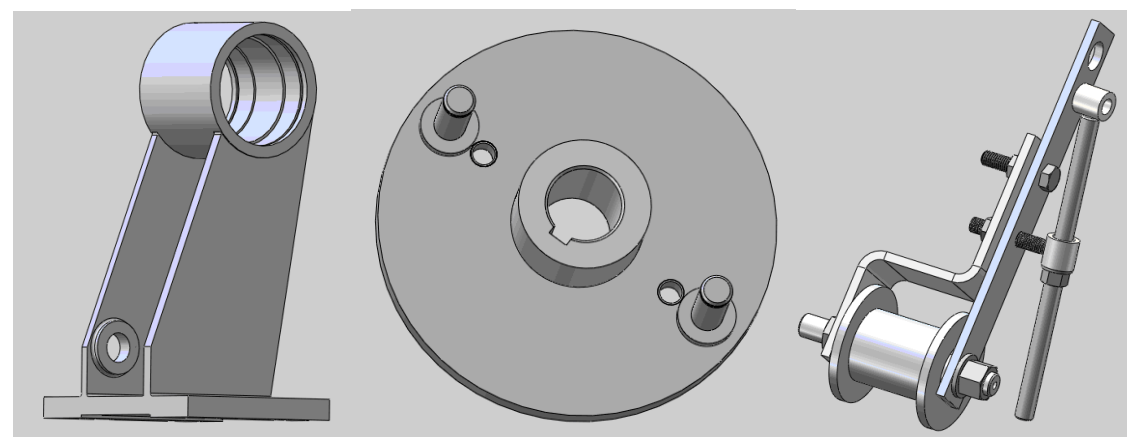

Fig. 2. Double disc mower three-dimensional model

According to the completed three dimensional parts model, using the design method of from bottom to top, the assembly of various components through constraints, cooperate relationship and order together, and finally the entire drive train components assemble the parts made use of 3D entity model. The final double disc mower the first level of the drive train assembly as is shown in Fig.3.

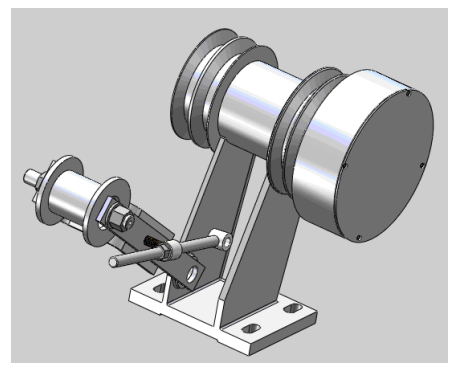

Fig. 3. Double disc mower assembly model

\subsection{Importing the Three-dimensional Model}

ANSYS for CAD/CAE collaborative environment can be read directly into a variety of CAD software part model, and in its unified environment to achieve arbitrary model assembly and CAE analysis, by connecting technology and sharing with CAD software. In this study, using the current professional graphics software SolidWorks to build the first level and the tension wheel drive system of the dual disc mower three-dimensional model, and then assembled. Through the seamless connection of 
the data between SolidWorks and workbench. Imported it into ANSYS Workbench, improving the efficiency of modeling, to prepare for finite element analysis.

Firstly, gray iron material was determined as the model material [6], Elastic Modulus is $\mathrm{E}=113 \mathrm{MPa}$, Tensile Strength is $\sigma=270 \mathrm{MPa}$, Density is $\rho=7.25 \mathrm{e} 3 \mathrm{~kg} / \mathrm{m} 3$, Poisson ratio is 0.25 , load is applied to the model, after analysis, the load of drive bracket mainly from the ends of the two belt drive transmitted to the pressure bearing, drive bracket to establish the center of the Cartesian coordinate system, the calculated equivalent in contact with the bearing load is applied to the inner surface.

Mesh Generation. Mesh Generation is the main work of finite element pretreatment, mesh quality and merits will have a considerable impact on the results, ANSYS Workbench meshing is more intelligent, there are a variety of control methods, this paper uses size control method to mesh Generation. In the division of the value set of smart sizing is $20 \mathrm{~mm}$ for free meshing, divided into 45,249 units and 75,462 nodes. Analysis mesh model as is shown in Fig.4.

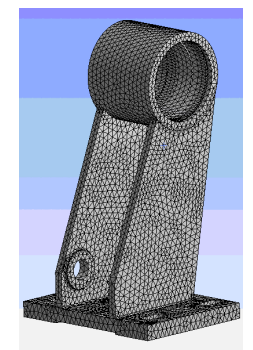

Fig. 4. Mesh generation model

Impose Constraints. Then set at a fixed constraint on stand base four holes, bearing contact with the inner surface of is given a vertical downward pressure, and a belt drive pressure, and contrary to the overall stent carry on drive and the local stress and strain analysis.

\section{Results and Discussion}

By the computer automatic calculation of the optimal final result, meanwhile Design Explorer offers, included response surface contour, response curve, sensitivity, and histogram display, including a variety of results [7, 8]. As is shown in Fig.5, materials were made of gray iron castings, and while the production is small batch, the production cost is too high, the safety factor is too large, we can take use ordinary carbon steel of welded parts as an alternative, so as to reduce production costs. As is shown Fig.6, Fig.7, Fig.8, We can see from the figure, the stress and strain are less than the allowable stress and strain, the maximum stress is about $174.03 \mathrm{MPa}$, these results reflect the relationship between different angles input parameters and output parameters. Laid the foundation for the subsequent topology optimization. 


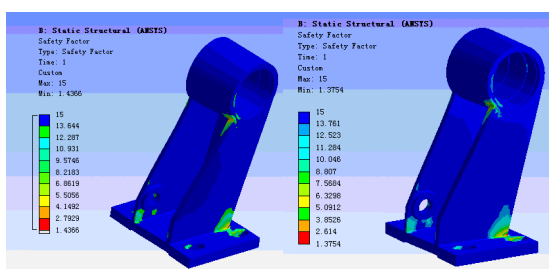

Fig. 5. Safety factor

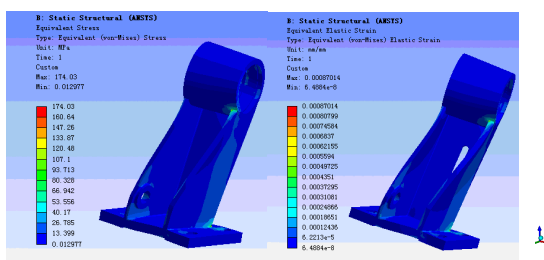

Fig. 7. Strain and stress Cloud images

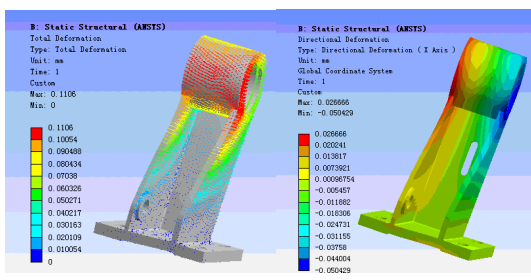

Fig. 6. Total strain and strain direction

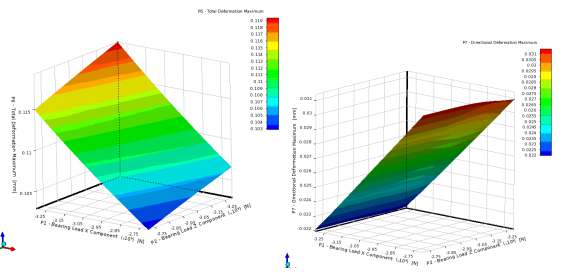

Fig. 8. Response surface Cloud images

Modal analysis technology is used to determine the design organization or vibration properties of machine parts, they are the important parameters in the design of structure under dynamic load.

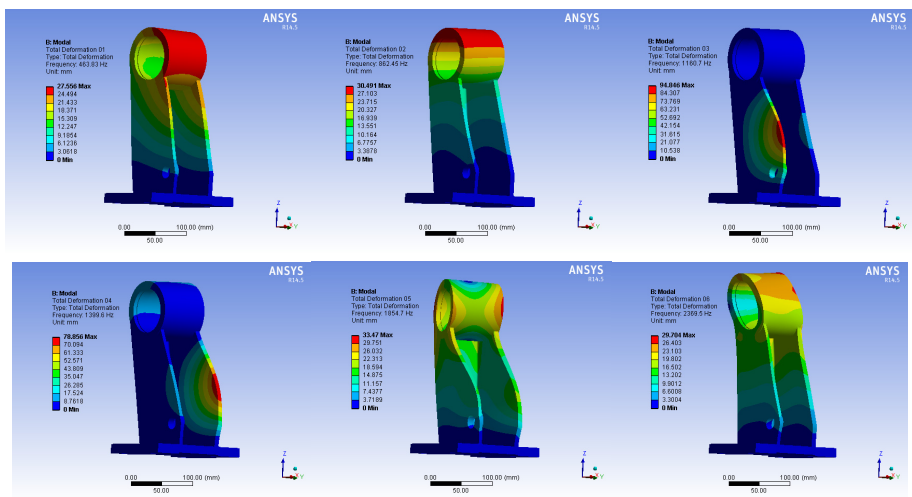

Fig. 9. The first to sixth order natural frequency displacement contours

Lawn mower drive bracket as an important component of dual disc mower, the strong vibration will cause the resonance of structures or fatigue, using ANSYS Workbench software for modal analysis, obtained the double disc mower characteristic of support the natural frequency and vibration mode of transmission, analyses the inherent frequency and vibration frequency displacement nephogram, As is shown Fig.9.

Under the action of the external excitation of bending, torsional vibration, not only caused the fatigue damage of primary vertical shaft, but also affected the smoothness 
of the overall transmission, we can see the natural frequency of the drive bracket is between $2369.5 \mathrm{HZ}$ and $463.83 \mathrm{HZ}$ to change, with the modes increase of the order of the natural frequency is also increased, the most of vibration is belongs to local vibration, local vibration mode illustrated its structure is low local stiffness, thickening the ligament may be appropriate to increase the structural stiffness and strength and make the structure change into the overall local vibration and improve the vibration characteristics of the drive bracket.

\section{Conclusions}

Results are shown that the development of virtual prototype technology creative the new theoretical analysis method, solved the multi-objective optimization request for multi-variable adjustment cannot be replaced by the physical prototype design means perfectly, using virtual design can significantly speed up the design progress, improve the quality of our product design for the subsequent design of agricultural machinery and provides a theoretical basis for vibration analysis. China's agricultural machinery design, due to the application of the finite element method and the development of experimental techniques have been gradually emerging from the rule of thumb approach. Structural optimization work in depth and more widespread, will further improve the design level of farm machinery, improved reliability and shorten the design cycle, so that guide the agricultural machinery design into a new phase.

Acknowledgment. Funds for this research was provided by the funds of national Agricultural science and technology achievement transformation (2009GB2A400054), the project financially aided by the funds to guide and encourage the science and technological creativeness of Inner Mongolia Autonomous Region (2010173).

\section{References}

1. Jerman, B., Kramar, J.: A study of the horizontal inertial forces acting on the suspended load of slewing cranes. International Journal of Mechanical Sciences 50, 490-500 (2008)

2. $\mathrm{Pu}, \mathrm{G} .:$ ANSYS Workbench 12 based tutorials and examples. China Water and Power Press, Beijing (2010) (in Chinese)

3. Zhang, G., Tian, Y.: Variable speed bicycle frame finite element analysis based on ANSYS Workbench. ITS Applications 28(6), 63-65 (2009) (in Chinese)

4. Shang, Y.: Principles and ANSYS FEM Application Guide, pp. 280-281. Tsinghua University Press, Beijing (2005) (in Chinese)

5. Qian, J.M., Jiang, X., Zhong, X., Fan, J.: Discussion on contact analysis based on ANSYS software problems. Mining Machinery 7, 69-72 (2006) (in Chinese)

6. Li, B., He, Z., Chen, X.: ANSYS Workbench design, simulation and optimization, pp. 850. Tsinghua University Press, Beijing (2008) (in Chinese)

7. Wu, Z., Wang, Y.: The Whole Hydraulic Support finite element analysis based on ANSYS Workbench. Mining Machinery 30(9), 106-107 (2009) (in Chinese) 
8. Wang, Y., Wang, P., Li, L.: The development of parametric modeling technology for truck frame. Agricultural Equipment Vehicle Engineering (4), 13-15 (2010) (in Chinese)

9. Xie, Z., Yu, S., Li, C., et al.: The handling robot structural optimization design based on ANSYS Workbench. Machinery \& Electronics (1), 65-67 (2010) (in Chinese)

10. Mao, X., Wen, T.: Based on finite element analysis, optimization design motorcycle frame. Motorcycle Technology 37(5), 35-37 (2007) (in Chinese)

11. Lu, L., Li, Y.: Virtual Prototyping Technology in Agricultural Machinery Design. Chinese Agricultural Mechanization (4), 59-61 (2004) (in Chinese)

12. Zu, X., Huang, H., Zhang, X.: Virtual Prototype Technology and Its Development. Agricultural Machinery 35(2), 168-171 (2004) (in Chinese) 